\title{
Maus-Tratos em Crianças e Adolescentes com Deficiência e/ou Perturbaçóes do Desenvolvimento ABUSEINCHILDRENANDADOLESCENTS WITHDISABILITIESAND/ORDEVELOPMENTAL
} DISORDERS

\author{
Vera CRUZ ${ }^{1}$ \\ Cristina P. ALBUQUERQUE ${ }^{2}$
}

\begin{abstract}
RESUMO: a presente investigação tem como principal objetivo analisar as características da associaçáo entre deficiência e/ou perturbaçôes do desenvolvimento e maus-tratos na população infanto-juvenil portuguesa, e destacar as respectivas implicações no domínio da educação especial. A amostra é constituída por 198 crianças e adolescentes com deficiência e/ou perturbações do desenvolvimento, que foram vítimas de maus-tratos. A informação foi recolhida através de um questionário, elaborado para este fim, e respondido por psicólogos e assistentes sociais. Em termos dos resultados obtidos, verificou-se que o maltrato misto (associaçáo entre duas ou mais formas de maltrato) foi o mais comum, seguindo-se a negligência. Os agentes de maltrato mais frequentes foram os progenitores. A detecção dos maus-tratos foi efetuada, em regra, na etapa pré-escolar, sendo as suas principais fontes as instituições/serviços que já acompanhavam a família. Foi também detectada uma elevada percentagem de problemas de saúde física e mental, de dependências e de dificuldades de inserçáo social nos pais destas crianças/adolescentes. A quase generalidade das crianças e famílias beneficiou de alguma intervenção após a sinalização dos maus-tratos. No que respeita a conclusôes, e uma vez que os maus-tratos tendem a ocorrer cedo e em famílias com múltiplos fatores de risco, apontam-se estratégias de intervençáo familiar e sublinha-se a importância que os programas de intervenção precoce podem revestir. Também se indica o papel que os professores podem desempenhar na detecção dos maus-tratos e realça-se a relevância e a composição dos programas direcionados para o ensino de estratégias de proteçấo e autodefesa.
\end{abstract}

PALAVRAS-CHAVE: Educação Especial. Violência. Deficiência.

\begin{abstract}
This study analyses characteristics of the association between disability and/or developmental disorders and abuse among Portuguese children and youth. It also underscores the consequences of this association for special education. The sample consists of 198 children and adolescents with disabilities and/or developmental disorders that were abused. The data was collected using a checklist designed specifically for this study, completed by psychologists and social workers. The results showed that the most frequent type of abuse was a combination of two or more types of maltreatment, followed by neglect. The most frequent perpetrators were the parents, who were also the children's main caretakers. Abuse was identified early, usually at age 4, and mainly by institutions or services that were already following the families. A high percentage of physical and mental health problems, substance abuse and social inclusion difficulties in the parents of these children and adolescents was also observed. After identification of abuse, almost all of these children and families benefitted from some kind of intervention. In conclusion, since abuse usually occurs early and in families with multiple risk factors, we indicate the need for family intervention strategies and highlight the importance of early childhood intervention programs. The role that teachers play in screening abuse is also pointed out, as well as the relevance of setting up programs directed towards the acquisition of self-protection skills.
\end{abstract}

KEYWORDS: Special Education. Violence. Disability.

\section{INTRODUÇÁo}

Atualmente verifica-se uma elevada e crescente visibilidade dos maus-tratos infantis, os quais são reconhecidos internacionalmente como um sério problema social, de desrespeito pelos direitos humanos e de saúde pública, que atinge e prejudica crianças e adolescentes

\footnotetext{
${ }^{1}$ Faculdade de Psicologia e de Ciências da Educação da Universidade de Coimbra, Portugal. veracruzinvestigacao@hotmail.com

${ }^{2}$ Professora Auxiliar, Faculdade de Psicologia e de Ciências da Educação da Universidade de Coimbra, Portugal. calbuquerque@ fpce.uc.pt
} 
durante um importante período do seu desenvolvimento. Em termos de delimitação, os maus-tratos remetem para uma situação em que se identifica a existência de um sujeito em condiçóes de superioridade relativamente à criança, independentemente da natureza dessa superioridade (hierárquica, força física, idade, inteligência, posição social ou económica), o qual comete dano (corporal, psicológico ou sexual), contra a vontade da vítima ou mesmo após o consentimento desta, quando tal for obtido por indução ou sedução enganosa (WORLD HEALTH ORGANIZATION, 2006). Para além das formas de violência que acabámos de referir (física, psicológica e sexual), os maus-tratos podem também assumir as formas de negligência e abandono.

Em Portugal, os maus-tratos assumem uma particular importância, uma vez que, em 2003 segundo a UNICEF, o país ocupou o primeiro lugar nos casos de maus-tratos a menores com consequências mortais, numa lista composta por 27 países industrializados. A mesma fonte referiu ainda que, anualmente no país, em cada cem mil crianças com menos de 15 anos, morriam 3,7 vítimas de negligência ou maus-tratos. Mais recentemente, a Comissão Nacional de Proteção de Crianças e Jovens em Risco (CNPCJR, 2012) indicou que, durante o ano de 2011, tinham sido caracterizadas 68478 situaçóes de perigo em relação a crianças e jovens.

Não obstante, em Portugal, os dados e estudos disponíveis dizem respeito exclusivamente a crianças e jovens sem qualquer problemática identificada. Ora, ao nível internacional, tem-se verificado a existência de uma maior vulnerabilidade aos maustratos nas crianças e jovens que evidenciam algum tipo de deficiência e/ou perturbação do desenvolvimento (GONZALVO, 2002; JONES et al., 2012; SOBSEY, 1994; SULLIVAN, 2009; SULLIVAN; KNUTSON, 2000a, 2000b). Assim, e segundo Gonzalvo (2002), os estudos realizados unicamente com crianças com deficiências têm revelado prevalências de maltrato que oscilam entre $9.7 \%$ e $61 \%$. Em complemento, a possibilidade de uma criança com deficiência ser vítima de maltrato é 3,4 vezes mais elevada do que a de uma criança normal (SULLIVAN; KNUTSON, 2000a). Por seu turno, Sullivan (2009) evidenciou que as perturbações de desenvolvimento (incluindo as dificuldades de aprendizagem, as perturbaçóes da comunicação e as perturbaçóes do comportamento) eram particularmente frequentes entre as crianças maltratadas (53.7\% em 1277 casos). Todavia, há que realçar que as perturbações do desenvolvimento têm sido menos estudadas do que as deficiências em termos das respetivas associaçóes à violência dos maus-tratos.

Apesar da vulnerabilidade das pessoas com deficiência e/ou perturbaçóes do desenvolvimento em relação aos maus-tratos ser elevada e estar documentada, esta não tem sido objeto de uma análise proporcional à investigação que se tem realizado sobre a temática dos maus-tratos em pessoas ditas normais. Por conseguinte, existem ainda vários parâmetros que não reúnem consenso, bem como tópicos insuficientemente investigados. No âmbito dos primeiros, referimos, a título exemplificativo, o tipo de maltrato(s) sofrido(s) e o(s) agente(s) do(s) mesmo(s). Assim, para alguns investigadores (CHILD WELFARE INFORMATION GATEWAY, 2001; GONZALVO, 2002, 2007; SCHORMANS; BROWN, 2002; SULLIVAN; KNUTSON, 2000b; VERDUGO; BERMEJO; FUERTES, 1995), a negligência é o tipo de maltrato mais comum, enquanto que outros investigadores, apontam a predominância do maltrato físico (AMMERMAN et al., 1989) ou do abuso sexual (PEDRO-VIEJO; GÓMEZBENGOECHEA, 2006). Nota-se, no entanto, que se tem atendido sobretudo aos diferentes 
tipos de maus-tratos individualmente considerados, contemplando-se pouco a presença simultânea de mais do que um tipo, isto é, o maltrato misto (GONZALVO, 2002, 2007; JONES et al., 2012; SCHORMANS; BROWN, 2002). No que se reporta aos agentes do maltrato nestes casos, tem-se notado que o maltratante é frequentemente um membro da família e, em particular, as mães biológicas (CHILD WELFARE INFORMATION GATEWAY, 2001; GONZALVO, 2002, 2007; SCHORMANS; BROWN, 2002; SULLIVAN; KNUSTON, 2000b). Todavia, tem-se também verificado que podem ser outros familiares (PREVENT CHILD ABUSE AMERICA, 2007) ou inclusivamente os profissionais e/ou prestadores de serviços (SOBSEY, 1994).

No que respeita a tópicos insuficientemente investigados ou ignorados no âmbito dos maus-tratos a crianças e jovens com deficiências e/ou perturbaçóes do desenvolvimento, apontam-se os referentes à idade de deteção do maltrato, às fontes de sinalização do mesmo e às intervençóes desenvolvidas quer junto da criança/jovem, quer junto da sua família. Por exemplo, embora estratégias de prevenção estejam identificadas para esta população específica (CHILD WELFARE INFORMATION GATEWAY, 2001; WORLD HEALTH ORGANIZATION, 2006), pouco se sabe sobre as que são efetivamente aplicadas num ou mais países.

\section{Presente Estudo}

A presente investigação tem como principal objetivo analisar as características da associaçáo entre deficiência e/ou perturbaçóes do desenvolvimento e maus-tratos na população portuguesa, mais especificamente numa amostra de crianças e adolescentes com estas problemáticas, residentes em dois concelhos portugueses. Assim, começam-se por analisar as características demográficas destas crianças e das suas famílias. Num segundo momento, procuram-se retratar as características do próprio maltrato [tipo, agente(s), caracterização dos progenitores da vítima, idade de deteção, responsáveis pela deteção] e identificar as diferentes formas de intervenção, isto é, circunscrever as medidas que foram adotadas em Portugal relativamente a estes casos. As implicaçóes de todos estes dados serão também realçadas, em particular no que respeita à educação especial. Pretende-se, ainda, determinar se existe alguma similitude, ou pelo contrário, divergência entre os resultados nacionais e os precedentes de outros países como os Estados Unidos da América (por ex., AMMERMAN et al., 1989; SULLIVAN, 2009; SULLIVAN; KNUTSON, 2000a, 2000b) e Espanha (p. ex., GONZALVO, 2002, 2007; VERDUGO, 2004; VERDUGO; BERMEJO; FUERTES, 1995), onde mais se tem estudado esta realidade.

\section{Método}

\section{Amostra}

Inicialmente selecionou-se um conjunto de 110 instituiçóes que se considerou integrarem nos seus estabelecimentos ou serviços crianças e/ou adolescentes com deficiência e/ou perturbações do desenvolvimento. Tratou-se de instituições de proteção a crianças/adolescentes (por ex., Santa Casa da Misericórdia de Lisboa), de reabilitação (por ex., Associação Portuguesa 
de Pais e Amigos do Cidadão Deficiente Mental), de saúde (por ex., Hospital Pediátrico de Coimbra) e de Lar (por ex., Casa do Pai).

Entre as 110 instituiçóes, responderam favoravelmente 48, se bem que em 27 delas se tivesse vindo a verificar a inexistência de casos de crianças/jovens com deficiência e/ou perturbaçóes do desenvolvimento que tivessem sido alvo de maus-tratos. Algumas instituições, designadamente 19, recusaram a sua participação em função de razóes variadas, tais como: elevada carga laboral; simultaneidade de investigaçóes a decorrer na mesma; falta de recursos humanos de modo a poder dar uma resposta à investigação. Outras 43 instituições não deram qualquer resposta ao pedido de participaçáo no presente estudo.

Em cada uma das instituiçôes participantes, solicitou-se aos respetivos técnicos que procedessem à identificação das crianças e jovens que satisfaziam as condições requeridas, e que colaborassem no preenchimento de um questionário relativo a cada um desses menores, o qual foi elaborado para o efeito e será descrito em seguida.

Este processo resultou numa amostra constituída por 198 crianças/adolescentes com deficiência(s) e/ou perturbações do desenvolvimento, que tinham sido vítimas de maus-tratos, das quais 124 (62.9\%) são do género masculino e 74 (37.4\%) são do género feminino. No que diz respeito ao nível etário, a amostra está compreendida entre os 4 meses e os 18 anos de idade, sendo os 10 anos a idade média $(M=10.02, D P=4.83)$. No entanto, a maior frequência de casos encontra-se na faixa etária dos 12 aos 18 anos $(n=87)$ e a menor entre os 0 e os 5 anos de idade $(n=45)$. Em termos de problemática, a amostra evidencia uma maioria de casos de Perturbação do Desenvolvimento (53.5\%), seguindo-se “ambas as situaçóes" com uma percentagem de 30.8\%, e por fim a situação de Deficiência com 15.7\%. A categoria "ambas as situaçóes" refere-se ao conjunto de crianças/adolescentes que apresentavam, ao mesmo tempo, pelo menos um diagnóstico de deficiência e de perturbação do desenvolvimento. É de ressalvar que, mais adiante, na apresentação dos resultados, será exposta uma caracterização mais detalhada das crianças e jovens, em termos da respetiva problemática.

\section{INSTRUMENTO}

De modo a recolher os dados, foi necessário proceder à elaboração de um questionário, uma vez que não existia nenhum instrumento disponível que se ajustasse, em simultâneo, aos objetivos desta investigação e à realidade nacional. Numa fase inicial, elaboraram-se várias versóes do questionário (3 no total), tendo-se atendido ao formato, à ordem e à clareza dos itens, à correção na respetiva redação e ainda ao aspeto gráfico do próprio questionário, optandose por um modelo A3 (HILL; HILL, 2005; MOREIRA, 2004). Num segundo momento, procurou-se verificar a adequação do questionário, tendo este sido submetido à análise de alguns técnicos (7) escolhidos aleatoriamente num contexto institucional. O questionário é constituído por 11 páginas, subdivididas quer em partes, quer em secçôes. Na primeira página, figura a apresentação do estudo e as instruçóes gerais de preenchimento. Na segunda página, são apresentados, através de um glossário, os conceitos fundamentais a ter em consideração na resposta ao questionário, como por exemplo: deficiência; perturbação/problema do/no desenvolvimento; maltrato psicológico; maltrato misto; negligência e abuso sexual. Procedeuse assim à operacionalização de conceitos de modo a evitar o enviesamento de respostas devido 
à visão/conhecimento que os inquiridos poderiam ter sobre a temática abordada. Ao longo de todo este processo, procurou-se sempre que esta operacionalização primasse simultaneamente pelo rigor, síntese e clareza. Por exemplo, a negligência foi delimitada como a situação em que as necessidades físicas básicas do menor (alimentação, vestuário, higiene, proteção e vigilância, educação e/ou cuidados médicos) não eram atendidas temporária ou permanentemente (ALBERTO, 2006; ARRUABARRENA; DE PAÚL, 1996).

Em termos de organização, o questionário está subdividido em duas grandes partes.

A primeira parte é composta por três secçóes e um total de 35 questóes. Estas têm como objetivo reunir informaçóes relativas a características pessoais, sociais e demográficas da criança/ adolescente e da sua família, assim como dados referentes à situação de maltrato propriamente dita (por ex., tipo, idade de deteção, agente). Além disso, esta parte do questionário recolhe informaçóes sobre os pais/família da criança, designadamente dados biográficos, relativos ao seu estado de saúde (por ex., problemas de saúde física e de saúde mental) e ajustamento psicossocial.

A segunda parte do questionário compreende um total de 16 questóes referentes a características atuais da criança/adolescente (por ex., necessidade de atenção), à situação presente da criança/adolescente em termos de onde e com quem vive e às medidas que foram tomadas após o conhecimento do maltrato.

É de notar que em qualquer uma das partes do questionário, se assegurou o total anonimato da criança/adolescente, da sua família e do respondente (por ex., não se solicitando nomes ou endereços), bem como a confidencialidade dos dados recolhidos.

O questionário, cuja organização acabámos de descrever, é constituído por perguntas quer de resposta aberta como de resposta fechada, predominando no âmbito das últimas os itens constituídos por alternativas, os quais procuraram sempre fornecer a maioria ou a totalidade das alternativas de resposta possíveis. Por exemplo, no que concerne à problemática da criança/adolescente, o respondente começava por assinalar se se tratava de uma deficiência, de uma perturbação do desenvolvimento ou de ambas as situaçóes. De seguida, e caso fosse uma criança/adolescente com deficiência, o respondente deveria indicar se era uma deficiência mental, uma deficiência sensorial (por ex., auditiva, visual, ou ambas), uma deficiência motora (por ex., paralisia cerebral, espinha bífida) ou outra deficiência.. Após esta questão, surgia outra relativa à perturbação do desenvolvimento, e em que o respondente deveria assinalar a alternativa ou alternativas correspondentes ao tipo específico de perturbação(s) do desenvolvimento que se encontrava $(\mathrm{m})$ presente(s). Para o efeito, o respondente dispunha de 10 alternativas de resposta: 3 eram referentes a Perturbações de Défice de Atenção e Comportamento Disruptivo, designadamente a Perturbação da Hiperatividade e Défice de Atenção (PHDA), a Perturbação do Comportamento e a Perturbação da Oposição e Desafio; 3 diziam respeito a Perturbações Globais do Desenvolvimento, nomeadamente a Perturbação Autística, a Perturbação de Asperger e o Atraso de Desenvolvimento; 2 eram relativas a Perturbaçóes da Comunicação, mais especificamente à Perturbação Específica do Desenvolvimento da Linguagem e ao Mutismo; 1 reportava-se às Perturbaçóes da Eliminação e englobava a Enurese; e, por último, Outra permitia ao respondente referir qualquer outra perturbação do desenvolvimento. 
Os respondentes foram, na sua grande maioria, Psicólogo(a)s (44.9\%) e Assistentes Sociais (37.4\%), se bem que também tenham respondido Educadores (10.6\%) e Diretores (6.6\%).

\section{Resultados}

Dada a amplitude e diversidade das informações que foram recolhidas, bem como os constrangimentos em termos de espaço disponível, limitar-nos-emos à apresentação de alguns dos resultados obtidos.

Assim, em termos da problemática das crianças/adolescentes e como já foi mencionado anteriormente, o maior número e percentagem de casos da amostra (106 casos, 53.5\%) foram obtidos na situação de perturbação do desenvolvimento, seguindo-se-lhe situações de comorbilidade entre a deficiência e as perturbaçóes do desenvolvimento (61 casos, 30.8\%), e por último, a situação deficiência (31 casos, 15.7\%).

Tabela 1 - Tipo de Problemática

\begin{tabular}{lcc}
\hline & $n$ & $\%$ \\
Deficiência $(n=114)$ & 72 & 63.1 \\
Mental & 21 & 18.4 \\
Sensorial & 12 & 10.5 \\
Motora & 9 & 7.9 \\
Outra & & \\
Perturbaçóes do Desenvolvimento $(n=296)$ & & \\
Défice de Atenção e Comport. Disruptivo & 121 & 40.9 \\
Globais & 106 & 35.8 \\
Comunicação & 36 & 12.1 \\
Eliminação & 28 & 9.5 \\
Outra & 5 & 1.6 \\
\hline
\end{tabular}

No entanto, embora existam 31 casos de crianças/adolescentes com deficiência, existe um total de 114 deficiências, resultantes essencialmente de situaçóes de comorbilidade, isto é, da presença de mais do que uma deficiência com e sem associação a uma perturbação de desenvolvimento. Como se pode observar na Tabela 1, a deficiência mental é a que apresenta maior prevalência entre as situaçóes de deficiência.

Tal como acabámos de descrever, os respondentes também assinalaram situações em que as crianças/adolescentes possuíam uma ou mais perturbaçóes, tendo-se registado um total de 296 perturbações do desenvolvimento. Este número deve-se à adição das situações que reportavam a uma ou mais perturbações e da situação "ambas as situaçôes". De entre estas perturbaçóes, as Perturbaçóes de Défice de Atenção e de Comportamento Disruptivo são as mais frequentes [recorda-se que englobam a Perturbação da Hiperatividade e Défice de Atenção (PHDA), a Perturbação do Comportamento e a Perturbação da Oposição e Desafio]. 
Tabela 2 - Tipo de Maltrato e Maltratante

\begin{tabular}{lcc}
\hline & Amostra $(N=198)$ \\
& $N$ & $\%$ \\
\hline Tipo de Maltrato & 4 & 2.0 \\
Fisíco & 7 & 3.5 \\
Psicológico & 67 & 33.8 \\
Negligência & 2 & 1.0 \\
Abandono & 2 & 1.0 \\
Abuso sexual & 116 & 58.6 \\
Misto & & \\
& & \\
Maltratante & 59 & 28.8 \\
Mãe Biológica & 10 & 5.1 \\
Pai Biológico & 1 & .5 \\
Pai Não Biológico & 79 & 39.9 \\
Ambos os progenitores & 3 & 1.5 \\
Outra pessoa & 9 & 4.5 \\
Um dos progenitores e outro & & \\
familiar & 6 & 3.0 \\
Um dos progenitores e outra & & \\
pessoa & & \\
Ambos os progenitores e & 19 & .5 \\
outro familiar & & \\
Mãe Biológica e Pai não & 5 & \\
Biológico & & \\
Pai Biológico e Mãe Não & & \\
Biológica & & \\
Máe Biológica, Pai Não Bio- & & \\
lógico e Outro Familiar & & \\
\hline
\end{tabular}

$\mathrm{Na}$ amostra em estudo, o tipo de maltrato mais prevalente foi o "Maltrato Misto" (58.6\%) seguindo-se a "Negligência" (33.8\%). Os maus-tratos menos representados foram o "Abandono" e o "Abuso Sexual", ambos com 1\%. Assim, verifica-se que as crianças e adolescentes sofrem simultaneamente mais do que um tipo de maltrato, e que só uma minoria parece ser vítima de um único tipo de violência. Através de uma análise mais detalhada, é possível referir que os 116 casos de "Maltrato Misto" englobam combinaçóes específicas, como é o caso do "maltrato físico, psicológico e da negligência” com 43 casos, seguindo-se a associação entre o "maltrato psicológico e a negligência" presente em 30 casos de crianças/adolescentes maltratados. O "maltrato físico e o psicológico" também revelaram alguma associação, estando presentes em 8 casos.

Tal como podemos verificar através da Tabela 2, os pais surgem como sendo as pessoas que mais efetuam o maltrato à criança/adolescente (39.9\%). Individualmente a "Mãe Biológica" surge como sendo o agente de maltrato mais prevalente em 59 dos casos (28.8\%). Somente em 6 casos é que o maltratante não foi um ou ambos os progenitores, pelo que é possível identificar 
e concluir que o agente de maltrato à criança/adolescente é alguém que integra o seu núcleo familiar.

Verificou-se ainda que, na ocasião do maltrato, a maioria dos cuidadores das crianças/ adolescentes eram os familiares, com destaque para toda a família (19.7\%) ou ambos os progenitores (26.3\%). No entanto, a mãe é a mais vezes referenciada, uma vez que, para além de integrar as duas situaçóes anteriores, também foi apontada quer isoladamente (29.3\%), quer acompanhada de outro cuidador (10.6\%). Já o pai assumiu o papel de cuidador num número restrito de casos $(4.5 \%)$, bem como outros familiares $(1 \%)$ ou pessoas $(8.5 \%)$.

Tabela 3 - Estado de Saúde dos Progenitores

\begin{tabular}{lcc}
\hline & Pai & Mãe \\
& $n(\%)$ & $n(\%)$ \\
Saúde Física e Mental & & \\
Deficiência Motora & $3(1.5)$ & $4(2.0)$ \\
Deficiência Sensorial & $1(0.5)$ & $4(2.0)$ \\
Doença Crónica & $16(8.1)$ & $26(13.1)$ \\
Doença do foro Mental & $15(7.6)$ & $59(29.8)$ \\
Deficiência Mental & $18(9.1)$ & $33(16.7)$ \\
Sem Alteraçóes & $145(73.2)$ & $72(36.4)$ \\
& & \\
Dependências & & \\
Alcoolismo & $48(24.2)$ & $32(16.2)$ \\
Consumo de Drogas & $36(18.2)$ & $32(16.2)$ \\
Problemas com o Jogo & $2(1.0)$ & $0(0)$ \\
Sem Alteraçóes & $112(56.6)$ & $134(67.7)$ \\
& & \\
Desajustamento Psicossocial & & \\
Prostituiçáo & $2(1.0)$ & $33(16.7)$ \\
Reclusáo & $11(5.6)$ & $6(3.0)$ \\
Criminalidade & $23(11.6)$ & $14(7.1)$ \\
Mendicidade & $12(6.1)$ & $18(9.1)$ \\
Desemprego & $46(23.2)$ & $74(37.4)$ \\
Outros & $9(4.5)$ & $8(4.0)$ \\
Sem Alteraçóes & $95(48)$ & $45(22.7)$ \\
\hline & &
\end{tabular}

Em relação aos pais, procurou-se avaliar a sua condição de saúde atual (física e mental), bem como eventuais dependências e indicadores de desajustamento psicossocial. No âmbito da saúde física atendeu-se à deficiência motora, à deficiência sensorial e à doença crónica, e no âmbito da saúde mental contemplaram-se as doenças do foro mental (por ex., depressão, esquizofrenia) e a deficiência mental. No que concerne aos problemas de dependência, considerou-se o alcoolismo, o consumo de drogas e os problemas com o jogo, enquanto que ao nível psicossocial se atendeu à prostituição, à reclusão, à criminalidade, à mendicidade, ao desemprego e a outras situaçóes de idêntica natureza que os técnicos das instituiçóes participantes considerassem oportuno assinalar. No que respeita à saúde física e mental, a Tabela 3 indica que 179 dos 396 progenitores $(45.2 \%)$ tiveram ou têm alguma doença/deficiência, com destaque para as 
mães (126 casos). Os problemas de saúde mental são os mais representados com 74 casos. No total foram relatados 150 casos com um ou mais problemas de dependência (37.8\%), dos quais 86 dizem respeito ao pai e 64 à mãe. O alcoolismo e o consumo de drogas revelaram ser as problemáticas com maior ocorrência. No entanto, o maior número de casos verificou-se ao nível do desajustamento psicossocial, tendo sido apontada uma ou mais situaçóes em 256 progenitores (64.6\%), das quais 103 dizem respeito ao pai e 153 à mãe. As situaçóes mais comuns são o desemprego $(n=120)$, a prostituição $(n=35)$ e a criminalidade $(n=37)$, estando as duas primeiras mais representadas na mãe e a última no pai.

Tabela 4 - Detetores do Maltrato

\begin{tabular}{lcc}
\hline \multirow{2}{*}{ Agentes } & \multicolumn{2}{c}{ Amostra $(N=198)$} \\
\cline { 2 - 3 } & $N$ & $\%$ \\
\hline Instituição/Serviço & 57 & 29 \\
Instituição/Profissionais de Saúde & & \\
Médico de família & 4 & 2.0 \\
Hospital & 28 & 14.1 \\
Médicos de família e outros & 18 & 9.1 \\
Hospital e outros & 8 & 4.0 \\
Total & 58 & 29.2 \\
Professores/Escolas & & \\
Professor & 24 & 12.1 \\
Professor e outros & 13 & 6.6 \\
Estabelecimento de infância/ & 7 & 3.5 \\
Creche & 44 & 22.2 \\
Total & 14 & 7.1 \\
Outros Agentes & 11 & 5.6 \\
Vizinhos ou Vizinhos e Outros & 11 & 5.6 \\
Familiar ou Familiar e Outros & 3 & 1.5 \\
Pais &
\end{tabular}

Os resultados obtidos indicam que a idade média em que foi detetado o maltrato à criança/adolescente é de $4.88(D P=3.97)$, sendo a idade mínima 1 dia e a máxima de 15 anos. Em termos dos agentes da deteção, é possível notar na Tabela 4, que o maltrato é relatado sobretudo por profissionais/instituiçóes de saúde, considerados quer individualmente, quer em conjunto com outros agentes (29.2\%). Com idêntico protagonismo, figura uma "Instituição/ Serviço" (29\%), com destaque para instituiçóes de proteção a menores (por ex., Santa Casa da Misericórdia de Lisboa, Comissão de Proteção de Crianças e Jovens). Os professores e as escolas ocupam também um lugar de referência (22.2\%). Já os pais apresentam uma taxa de deteção muito baixa $(1.5 \%)$, equivalente a 3 casos. 
Tabela 5 - Situação Atual e Tipo de Intervenção

\begin{tabular}{lcc}
\hline & $N$ & $\%$ \\
Situação atual da criança/jovem & & \\
Vive com a família & 106 & 53.6 \\
Institucionalizada em regime de internato & 37 & 18.7 \\
Institucionalizada em regime de semi-internato & 2 & 1.0 \\
Está numa família de acolhimento & 1 & .5 \\
Foi adotada & 2 & 1.0 \\
Acolhida com Medida de Promoção e Proteção & 44 & 22.3 \\
Outra & 6 & 3.0 \\
& & \\
Tipo de Intervenção & & \\
A criança foi retirada à família & 27 & 13.6 \\
A criança/adolescente foi institucionalizado & 90 & 45.5 \\
Programas e/ou actividades para aumentar a autoestima & 92 & 46.5 \\
Programas e/ou actividades de defesa em situaçóes futuras & 24 & 12.1 \\
Acompanhamento à família por profissionais & 160 & 80.8 \\
Formação parental e/ou aos cuidadores sobre sinais de maus-tratos & 63 & 31.8 \\
Outras intervençóes & 57 & 28.8 \\
\hline
\end{tabular}

No que concerne à situação atual da criança (conferir Tabela 5), os respondentes ao questionário relataram que em $53.6 \%$ dos casos a criança/adolescente que foi vítima de maltrato vive com a sua família. Houve também um elevado número de respondentes que afirmaram que a criança se encontrava acolhida com uma Medida de Promoção e Proteção ( $n$ = 44), o que significa que a criança se encontra numa instituição e beneficia de uma ou mais medidas específicas que visam promover a sua segurança, saúde, formação, educação, bem-estar e desenvolvimento (por ex., apoio aos pais, educação parental).

Em relação à intervenção efetuada, os resultados, apresentados na Tabela 5, demonstram que devido à situação de maltrato de que a criança/adolescente foi vítima, a maioria 98.5\% ( $n$ $=195)$ recebeu intervenção, contra $1.5 \%(n=3)$ que não recebeu qualquer intervenção. Na sua grande maioria os respondentes assinalaram mais do que um tipo de intervenção por criança/ adolescente que tinha sido vítima de maltrato. Como é possível verificar, o acompanhamento à família da criança/adolescente realizado pelos profissionais ( $n=160,80.8 \%$ dos casos), a institucionalização ( $n=90,45.5 \%$ dos casos) e a participação em programas e/ou atividades para aumentar a autoestima (em 46.5\%,n=92) foram as intervençóes mais frequentes. Inversamente, a participação em programas e/ou atividades que ensinem a criança a defender-se em situações futuras $(12.1 \%$ dos casos, $n=24)$ e a retirada da criança/adolescente do seu núcleo familiar (13.6\% dos casos, $n=27$ ) surgiram como as menos frequentes.

Em 28.8\% ( $n=57)$ dos casos foram realizadas outras intervençôes, de natureza muito diversificada, como por exemplo: (1) acompanhamento psicológico ao menor; (2) integração da criança/adolescente num estabelecimento educativo adequado às suas necessidades; (3) acompanhamento mais específico e sistemático nas suas dificuldades, como terapia da 
fala/língua gestual; (4) acompanhamento aos pais nos problemas relacionados com as suas dependências; (5) acompanhamento sistemático de outros serviços (por exemplo, CPCJ).

\section{Discussão}

Queremos começar por salientar a relatividade com que os resultados obtidos devem ser entendidos, na medida em que foram descritos por um conjunto de técnicos, e não foram alvo de qualquer outra verificação. Além disso, não pudemos deixar de ter presente que não obstante se terem contactado 110 instituiçóes, apenas se obtiveram respostas favoráveis de 48. Assim sendo, o presente estudo representa necessariamente uma primeira aproximação à realidade portuguesa dos maus-tratos a crianças/adolescentes com deficiências/perturbaçôes do desenvolvimento.

À semelhança dos estudos internacionais que realçam que as crianças com algum tipo de deficiência e/ou perturbação do desenvolvimento possuem uma elevada vulnerabilidade na ocorrência de maus-tratos (GONZALVO, 2002; SOBSEY, 1994; SULLIVAN, 2009; SULLIVAN; KNUTSON, 2000a, 2000b), o presente estudo também evidenciou uma forte associação entre estas problemáticas e a violência contra elas cometida. As perturbaçóes do desenvolvimento, e no seio destas as Perturbações de Défice de Atenção e Comportamento Disruptivo, bem como as situaçóes de comorbilidade entre a deficiência e as perturbaçóes do desenvolvimento, ocupam um lugar de destaque. Apesar destes resultados serem consonantes com os apontados por Sullivan e Knutson (2000a) e por Ammerman et al. (1988, 1989) no que concerne respetivamente aos problemas de comportamento e à coexistência de diferentes perturbações, há que ter presente que a natureza transversal do presente estudo impossibilita o estabelecimento de qualquer relação causal unidirecional.

Em termos de tipo de maltrato, o maltrato misto (associação entre duas ou mais formas de maltrato) foi o mais comum nas 198 crianças e adolescentes em estudo (58.5\%,), seguindo-se a negligência (33.3\%). Estes dados vão de encontro aos indicados por outros autores (GONZALVO, 2002, 2007; JONES et al., 2012; SCHORMANS; BROWN, 2002), uma vez que estes também verificaram a associação entre dois ou mais tipos de maltrato num número apreciável dos casos por eles estudados. No entanto, e como já tivemos oportunidade de apontar, os diferentes tipos de maltrato têm sido investigados sobretudo de modo isolado (AMMERMAN et al., 1989; PEDRO-VIEJO; GÓMEZ-BENGOECHEA, 2006; SULLIVAN; KNUTSON, 2000b; VERDUGO; BERMEJO; FUERTES, 1995). Visto que uma criança que sofre pela primeira vez maus-tratos normalmente sofre um novo abuso, o elevado número de casos de maltrato misto nesta investigação, faz-nos crer que uma criança que é maltratada uma vez com uma forma de maltrato, é muitas vezes alvo de outros tipos de maus-tratos, associados ente si.

A presente investigação verificou que o(s) cuidador(es) da criança são usualmente a figura de maltrato, uma vez que foram os pais $(39.9 \%)$ ou a mãe $(28.8 \%)$ quem mais infligiu os maustratos e que estes eram também os cuidadores mais comuns da criança. Idênticos resultados foram apontados por outros autores (AMMERMAN et al., 1989; CHILD WELFARE INFORMATION GATEWAY, 2001; GONZALVO, 2002, 2007; SCHORMANS; BROWN, 2002; SOBSEY, 1994; SULLIVAN; KNUTSON, 2000a; VERDUGO; BERMEJO; FUERTES, 1995). 
Ao nível da caracterização dos pais, destacam-se as dificuldades de inserção social, patentes no desemprego e nas práticas ilícitas, entre as quais sobressai a prostituição feminina e a criminalidade masculina. A estas dificuldades acrescentam-se ainda as doenças de saúde física ou mental dominantes na mãe, assim como os problemas de dependência patentes essencialmente no pai. Emerge, assim, a imagem de pais com diversas fragilidades, a qual é consonante com a pesquisa disponível e abrange os fracos recursos económicos, inerentes ao desemprego (AMMERMAN et al., 1988), as práticas ilícitas (SCHORMANS; BROWN, 2002), o abuso de substâncias (GONZALVO, 2007; SCHORMANS; BROWN, 2002; SOBSEY, 1994; VERDUGO; BERMEJO; FUERTES, 1995) e as condiçóes de saúde debilitadas (GONZALVO, 2007; HIBBARD; DESCH, 2007; SCHORMANS; BROWN, 2002; SOBSEY, 1994; VERDUGO, 2004).

Em relação à idade média em que foi detetado o maltrato à criança/adolescente é de salientar que se trata de uma idade relativamente precoce, o que, por um lado, assinala que em famílias com vulnerabilidades de diversa ordem, a presença de uma criança com deficiência e/ou perturbação do desenvolvimento pode, desde cedo, exceder os recursos familiares. Por outro lado, uma tal precocidade assinala a possibilidade de se intervir desde logo, evitando a perpetuação dos maus-tratos.

Já em relação aos agentes de deteção do maltrato, os resultados alcançados remetem para que a fonte de sinalização do problema seja, usualmente de origem exterior ao contexto familiar da criança/jovem, nomeadamente, os profissionais/instituiçóes de saúde, a Instituição/ Serviço que acompanha a criança/jovem, os professores e as escolas. Já os pais apresentam uma taxa de deteção muito baixa, o que se prende com o facto dos maltratantes serem, sobretudo, eles próprios. Os familiares e os vizinhos também sinalizam pouco, o que evidencia a necessidade de, em Portugal, se dever continuar a sensibilizar as famílias alargadas e a própria comunidade para a função importante que poderão desempenhar a este nível.

Os professores também poderão desempenhar um papel mais importante na deteção do maltrato, já que passam muitas horas com as crianças e conhecem o seu processo de desenvolvimento, estando, por isso, em excelentes condições para verificar se há indicadores de maus-tratos ou fatores de risco na própria criança e na sua família (AZEVEDO; MAIA, 2006). Assim sendo, e em relação à própria criança, os professores deverão ter em conta os sinais óbvios dos maus-tratos ou as alterações objetivas da saúde física da criança. Por exemplo, o abuso físico pode manifestar-se através de lesóes visíveis, enquanto na negligência se tende a verificar atraso ou baixo crescimento e carência de higienização. Além disso, e uma vez que nem todos os tipos de maus-tratos se manifestam de forma tão óbvia, os professores deverão estar particularmente atentos a indicadores inespecíficos que refletem situaçóes anómalas e que, em contexto escolar, podem assumir, entre outras, as seguintes formas: absentismo injustificado ou repetido; comportamentos que visam chamar a atenção; mudanças inesperadas no desempenho académico; défices de atenção; dificuldades na realização das tarefas escolares; tristeza, desânimo, desconfiança e/ou medo; isolamento e pobre relacionamento com as outras crianças; agressividade verbal ou física; comportamentos sexualizados ou comentários sexuais inadequados para a idade (AZEVEDO; MAIA, 2006). 
A fim de detetarem os maus-tratos, é também essencial que os professores estejam atentos a fatores de risco, designadamente aos relativos aos pais da criança, tal como o ilustram os resultados referentes à caracterização dos pais obtidos no presente estudo. Em complemento, os professores deverão também estar alertas em relação aos apoios de que os pais dispóem (ex., isolamento pessoal e/ou social), bem como ao exercício das funçóes parentais (ex., perceção extremamente negativa da criança; vinculação frágil; correção física ou verbal exagerada; ALGOOD et al., 2011; AZEVEDO; MAIA, 2006). É também importante sensibilizar os professores para a importância de, em casos de crianças com deficiência e/ou perturbaçóes do desenvolvimento, evitarem desculpabilizar os pais devido à situação com que estes se defrontam, bem como para evitarem desvalorizar os sinais/indicadores inespecíficos que a criança apresenta (por ex., uma lesão corporal ser entendida como resultando da deficiência infantil).

A propósito da situação atual da criança e jovem, o presente estudo obteve resultados satisfatórios na medida em que das 198 crianças, a maioria recebeu acompanhamento e intervenção após a sinalização das situações. As situações de adoção ou de acolhimento numa família foram as menos referidas, possivelmente dada a pouca celeridade destes processos em Portugal, bem como o número diminuto de pais que se revelam disponíveis para adotar uma criança com deficiência e/ou perturbação do desenvolvimento.

Relativamente às intervençóes propriamente ditas, foram realizadas com alguma frequência mais do que uma. $\mathrm{O}$ acompanhamento à família da criança/adolescente realizado por profissionais foi o que registou um maior número de casos $(80.8 \%)$, o que traduz que se privilegia uma modalidade de intervenção centrada na família, e nas respetivas necessidades.

Já a participação das vítimas em programas e/ou atividades que a ensinem a defender-se em situaçóes que possam surgir ulteriormente foi uma das intervençóes menos implementada. Este último dado é insólito por duas ordens de razóes. Em primeiro lugar, porque estas crianças/adolescentes, algumas com dificuldades em expressar o que lhes acontece, continuam sem ter oportunidades de poder criar estratégias de defesa e/ou de proteção ou de serem sensibilizadas em relação a eventuais situações de maus-tratos. Em segundo lugar, porque existe evidência de que é possível ensinar aptidóes de proteção a crianças/jovens com deficiência, isto é, comportamentos verbais e não verbais que permitem evitar um dano potencial ao próprio, ou abandonar ou terminar uma situação de dano efetivo para o próprio (DOUGHTY; KANE, 2010). Estas aptidóes incluem identificar situações e comportamentos como perigosos e inaceitáveis, evitá-los ou fugir-lhes, e se tal se revelar impossível, comunicá-los a um adulto adequado para esse fim. Estas aptidóes podem ser complementadas com aptidóes sociais, e os professores, com destaque para os de educação especial, desempenham um papel essencial no seu ensino. Por seu turno, o ensino pode centrar-se no treino de comportamentos específicos, na capacidade de identificar e resolver problemas, ou em ambos (DOUGHTY; KANE, 2010).

Em relação a qualquer uma das intervençóes implementadas, é necessário ter presente que não se inquiriu sobre as respetivas modalidades de aplicação ou a respetiva eficácia na ótica de todos ou de parte dos nelas envolvidos. Assim sendo, desconhece-se, por exemplo, em que medida o acompanhamento à família da criança/adolescente contempla uma intervenção abrangente e concertada ao nível das interaçóes pais/criança, dos fatores de stresse parental e das redes de apoio social formal e informal (ALGOOD et al., 2011). 
Além disso, e face à constatação de que os maus-tratos tendem a ocorrer cedo e a ser detetados em média aos 4 anos de idade, urge sublinhar a importância que os programas de intervenção precoce podem revestir. Com efeito, e apesar de não terem sido mencionados pelos respondentes no presente estudo, estes programas atuam tipicamente junto de famílias que apresentam múltiplos fatores de risco, tal como as que foram previamente retratadas (ASAWA; HANSEN; FLOOD, 2008). O facto de, em Portugal, existir um Sistema Nacional de Intervenção Precoce na Infância, e destes programas terem múltiplos focos de intervenção constituem vantagens adicionais.

Ainda em relação às estratégias de intervenção familiar, consideramos que elas devem ser direcionadas, em primeiro lugar, para aumentar a consciência da família sobre o problema, isto é, auxiliá-la a ter uma perceção da possibilidade de alteração da situação com base em recursos pessoais (por ex., autoestima parental, competências comunicacionais), familiares, sociais/comunitários (por ex., serviços de apoio à família e à criança), e económicos (ex.: em termos de apoios estatais ou outros). Em segundo lugar, deveriam providenciar-se programas educacionais ao longo do desenvolvimento da criança (GONZALVO, 2004), que atuassem de forma preventiva, isto é, através do treino de competências pessoais e parentais que levassem a um maior conhecimento e compreensão do desenvolvimento da criança e da sua situação, criando expetativas de desenvolvimento realistas e positivas face à problemática da criança, sobretudo porque a maioria dos casos de maus-tratos a crianças com deficiência ocorrem dentro do contexto familiar. Estes programas também poderiam facilitar o acesso a recursos e serviços de intervenção precoce, de saúde (ex.: recurso a técnicas de reabilitação), de natureza social (ex.: instituiçóes de solidariedade ou associaçóes de pais como forma de reduzir o isolamento), de índole educacional (ex.: conhecimento de serviços de auxílio em situaçóes de crise ou técnicas para reduzir o stress) e de gestão do tempo (ex.: recursos disponíveis para auxiliar os familiares nas tarefas domésticas e/ou na substituição temporária dos mesmos para evitar uma sobrecarga do cuidador).

\section{Conclusóes}

Tanto quanto é do nosso conhecimento, esta é a primeira investigação que incide direta e exclusivamente sobre os maus-tratos a crianças e jovens portugueses com deficiência e/ou perturbaçóes do desenvolvimento. Evidencia que os maus-tratos são uma realidade nesta população, assumindo múltiplas formas em simultâneo, e sendo perpetrados predominantemente pelos pais, os quais tendem a evidenciar problemas psicossociais graves. Neste contexto, a presença de uma deficiência ou de uma perturbação do desenvolvimento poderá representar um fator de stresse adicional, num sistema já de si frágil e/ou sobrecarregado. Assim, urge identificar, referenciar e apoiar o mais precocemente possível estas crianças e famílias.

\section{REFERÊNCIAS}

ALBERTO, I. M. Maltrato e trauma na infância. Coimbra: Almedina, 2006.

ALGOOD, C. I., et al. Maltreatment of children with developmental disabilities: An ecological systems analysis. Children and Youth Services Review, New York, v. 33, n. 7, p. 1142-1148, 2011. 
AZEVEDO, M. C.; MAIA, A. C. Maus-tratos à criança. Lisboa: Climepsi, 2006.

AMMERMAN, R. T. et al. Maltreatment of children and adolescents with multiple handicaps: five case examples. Journal of the Multihandicapped Person, New York, v. 1, n. 2, p. 129-139, 1988.

AMMERMAN, R. T. et al. Abuse and neglect in psychiatrically hospitalized multihandicapped children. Child Abuse \& Neglect, Oxford, v. 13, n. 3, p. 335-343, 1989.

ARRUABARRENA, M.; DE PAÚL, J. Manual de protección infantil. Barcelona: Masson, 1996.

ASAWA, L. E.; HANSEN, D. J.; FLOOD, M. F. (2008). Early childhood intervention programs: Opportunities and challenges for preventing child maltreatment. Education and Treatment of Children, Pittsburgh, v. 31, n. 1, p. 73- 110.

CHILD WELFARE INFORMATION GATEWAY. The risk and prevention of maltreatment of children with disabilities, 2001. Disponível em: http://childwelfare.gov/pubs/prevenres/focus. Acesso em: 7 jul. 2011.

COMISSÃO NACIONAL DE PROTECÇÃO DAS CRIANÇAS E JOVENS EM RISCO. Relatório anual de avaliação da atividade das Comissóes de Proteção de Crianças e Jovens no ano de 2011, 2012. Disponível em: http://www.cnpcjr.pt/preview_documentos.asp?r=3795\&m=PDF. Acesso em: 7 jul. 2012.

DOUGHTY, A. H.; KANE, L. M. Teaching abuse-protection skills to people with intellectual disabilities: A review of the literature. Research in Developmental Disabilities, Amesterdam, v. 31, n. 2, p. 331-337, 2010GONZALVO, G. O. Maltrato en niños con discapacidades: características y factores de riesgo. Anales de Pediatría, Barcelona, v. 56, n. 3, p. 219-223, 2002.

GONZALVO, G. O. Qué se puede hacer para prevenir la violencia y el maltrato de los nińos con discapaciades? Anales de Pediatria, Barcelona, v. 62, n. 2, p. 153-157, 2004.

GONZALVO, G. O. Características y fatores de riesgo del maltrato en adolescentes con discapacidades. Compumedicina, Madrid, v. 8, n. 131, p. 1-5, 2007.

HIBBARD, R. A.; DESCH, L. W. Maltreatment of children with disabilities. Pediactrics, Elk Grove Village, v. 119, n. 5, p. 1018-1025, 2007.

HILL, M. M.; HILL, A. Investigação por Questionário. Lisboa: Edições Sílabo, 2005.

JONES, L. et al. Prevalence and risk of violence against children with disabilities: a systematic review and meta-analysis of observational studies. The Lancet, London, v. 380, n. 8, p. 899-907, 2012.

MOREIRA, J. M. Questionários: Teoria e prática. Coimbra: Ediçóes Almedina, 2004.

PEDRO-VIEJO, A. B.; GÓMEZ-BENGOECHEA, B. Los menores con discapacidad como víctimas de maltrato infantil: una revisión. Intervención Psicosocial, Madrid, v. 15, n. 3, p. 293-306, 2006.

PREVENT CHILD ABUSE AMERICA. Maltreatment of children with disabilities, 2007. Disponível em: http://www.preventchild abuse.org. Acesso em: 7 jul. 2011.

SCHORMANS, A. F.; BROWN, I. An investigation into the characteristics of the maltreatment of children with developmental delays and the alleged perpetrators of this maltreatment. The Journal on Developmental Disabilities, Toronto, v. 9, n. 1, p. 1-19, 2002.

SOBSEY, D. Violence and abuse in the lives of people with disabilities: The end of silent acceptance? Baltimore: Paul H.Brookes Publishing, 1994. 
SULLIVAN, P. M. Violence exposure among children with disabilities. Clinical Child and Family Psychology Review, New York, v. 12, n. 2, p. 196-216, 2009.

SULLIVAN, P. M.; KNUTSON, J. F. Maltreatment and disabilities: a population-based epidemiological study. Child Abuse \& Neglect, Oxford, v. 24, n. 10, p. 1257-1273, 2000a.

SULLIVAN, P. M.; KNUTSON, J. F. The prevalence of disabilities and maltreatment among runaway children. Child Abuse \& Neglect, Oxford, v. 24, n. 10, p. 1275-1288, 2000 b.

UNICEF. Innocenti Report Card No. 5. Florence: UNICEF Innocenti Research Centre, 2003.

VERDUGO, M. A. Maltrato y violencia de género en personas con discapacidad intelectual. Estrategias de prevención. In: SEMINÁRIO VIOLENCIA DE GÉNERO Y DISCAPACIDADES, 7-8 Mayo, 2004, Vitoria-gasteiz, Disponível em http://www.eraberri.org/archivos/ponencias Acesso em: 12 fev. 2011.

VERDUGO, M. A.; BERMEJO, B. G.; FUERTES, J. The maltreatment of intelectually handicapped children and adolescents. Child Abuse \& Neglect, Oxford, v. 19, n. 2, p. 205-215, 1995.

WORLD HEALTH ORGANIZATION. Preventing child maltreatment: a guide to taking action and generating evidence, 2006, Disponível em: WHO:http://www.who.int/violence_injury_prevention/ publications/violence/child_maltreatment/en/index.html Acesso em: 12 fev. 2011.

Recebido em: 26/10/2012

Aprovado em: 30/04/2013 